\title{
Befindlichkeit e Stimmung, das tonalidades afetivas na analítica existencial de Heidegger
}

\section{Befindlichkeit e Stimmung, on Attunements in Heidegger's Existential Analytics}

DOI: 10.12957/ek.2020.49403

\author{
Dr. Roberto S. Kahlmeyer-Mertens \\ kahlmeyermertens@gmail.com \\ Universidade Estadual do Oeste do Paraná
}

\author{
Ms. Giovani Augusto dos Santos \\ augusto.santos49@gmail.com \\ Universidade São Francisco
}

\section{RESUMO}

As tonalidades afetivas são tema do presente trabalho. Ao abordá-las, em sua obra Ser e tempo, Heidegger utiliza Befindlichkeit e Stimmung para nomear uma experiência de afinação ontológica. Antes de definir aqui o que isso poderia significar, nosso artigo objetiva primeiramente analisar esses fenômenos e os conceitos que os expressam no âmbito da analítica existencial presente naquela obra. O problema orientador do artigo se ocuparia essencialmente em indagar: o que o filósofo quer indicar com os termos Befindlichkeit e Stimmung? Para uma tal problematização, optamos por recorrer inicialmente a uma revisão de literatura na qual se passará em revista as escolhas de tradução dos termos em apreço especificamente em Ser e tempo. $\mathrm{O}$ objetivo desse momento é o de indicar que, embora sejam expressões de difícil tradução, é possível pensá-los de maneira acurada (e em coerência ao modo de dizer heideggeriano) em face dos termos utilizados para verter sua conceptualidade ao português. Adiante, pretendemos expor o quanto Befindlichkeit e Stimmung seriam fenômenos correlatos. Associado a isso, planejamos rematar o estudo com uma indicação do papel que as tonalidades afetivas desempenhariam frente a noção de ser-lançado (Geworfenheit), pesquisando quais implicações tais fenômenos próprios à existência do ser-aí teriam perante a abertura constitutiva deste ao mundo e a sua facticidade específica.

\begin{abstract}
Attunement are the subject of this work. In treating them, in his work Being and Time, Heidegger uses Befindlichkeit and Stimmung to name an experience of ontological tuning. Before defining here what this could mean, our article first aims to analyze these phenomena and the concepts that express them in the scope of the existential analytics present in that work. The guiding problem of this article deals with the following question: what does the philosopher mean by the terms Befindlichkeit and Stimmung? For such problematization, we opted to initially resort to a literature review in which the translation choices of the terms in question will be reviewed specifically in Being and Time. The aim of this new moment is to indicate that, although they are difficult to translate, it is possible to think them accurately (and in coherence with the Heideggerian way of saying) in the face of the terms used to translate their conceptuality into Portuguese. Ahead, we intend to explain how much Befindlichkeit and Stimmung would be related phenomena. We plan to end the study with an indication of the role that attunements would play against the notion of being-launched (Geworfenheit), researching what implications such phenomena proper to the existence of being-there would have before the constitutive opening of this to the world and their specific facticity.
\end{abstract}

Palavras-chave: Befindlichkeit. Stimmung. Tonalidades Afetivas. Analítica Existencial. Heidegger. Keywords: Befindlichkeit. Stimmung. Attunement. Existential Analytic. Heidegger. 
| Artigo | Befindlichkeit e Stimmung, das tonalidades afetivas na analítica existencial de Heidegger |

| Dr. Roberto S. Kahlmeyer-Mertens \& Ms. Giovani Augusto dos Santos |

\section{Introdução}

É mais que consabido que o projeto filosófico primordial da obra do filósofo alemão Martin Heidegger (1889-1976) é o da recolocação da questão do ser. Tal noção, e o questionamento a seu respeito, se faz presente já nas origens do pensamento ocidental, mas, em certa medida, este acabou por ser esquecido e mesmo negligenciado ao longo de sua história. É em resposta a esta carência que vem Ser e tempo, obra que assume para si a tarefa de empreender uma ontologia fundamental, esta dependente de uma analítica existencial, enquanto etapa necessária à recolocação da questão. Em face dessas indicações preliminares, podemos indagar, com o fito de delimitar o tema que nosso título anuncia: qual o interesse de Heidegger - auto declaradamente um filósofo do ser - em relação às tonalidades afetivas? Como as assim chamadas tonalidades afetivas estariam implicadas à analítica existencial e, antes mesmo, à ontologia fundamental?

O tema das tonalidades afetivas está presente em parte considerável do pensamento de Heidegger, aparecem em textos do início da década de 1920, como por exemplo no curso do semestre de verão de 1921, intitulado Agostinho e o neoplatonismo, e continuam a repercutir em obras posteriores a Ser e tempo, ao exemplo de Contribuições à filosofia, obra escrita entre os anos de 1936 e 1938 e se encontra ainda em 1966, nos Seminários de Zollikon, como objeto de consideração.

No presente artigo, nosso objetivo é uma análise das tonalidades afetivas, para tanto, nos deteremos na descrição fenomenológica feita por Heidegger no $\$ 29$ de Ser e tempo, intitulado $O$ ser-aí como afinação (Das Da-sein als Befindlichkeit), no qual o filósofo apresenta tais tonalidades como constitutivas do ser-aí. Atentos à amplitude do tema e cientes de que uma tematização pontual desse objeto não pode se estender mais do que um passo, delimitamos o campo temático do presente artigo em torno da tarefa de apresentar dois conceitos fenomenológicos utilizados por Heidegger, a saber: Befindlichkeit e Stimmung. Tal opção se justifica pelo fato de não ser possível falar de "afeto" na analítica existencial do ser-aí sem se ver implicado, primeiramente, a esses dois fenômenos. 
| Artigo | Befindlichkeit e Stimmung, das tonalidades afetivas na analítica existencial de Heidegger |

| Dr. Roberto S. Kahlmeyer-Mertens \& Ms. Giovani Augusto dos Santos |

\section{Em torno à terminologia dos "afetos"}

Uma análise do fenômeno aqui enfocado se beneficia das descrições de Heidegger e é precisamente delas que partimos. De início, nos diz Heidegger (2015): "O que indicamos ontologicamente com o termo encontrar-se (Befindlichkeit) é, onticamente, o mais conhecido e o mais cotidiano, a saber, a tonalidade afetiva (die Stimmung), o estar-afetado (das Gestimmtsein)" (p.193), percebamos que logo na primeira frase do parágrafo se apresenta a afetividade em Ser e tempo. As palavras Befindlichkeit e Stimmung, aludidas por Heidegger, estão em foco e já se mostram como difíceis de traduzir, pois (em português, por exemplo) não se encontram correlatos que denotem os mesmos significados empregados por Heidegger. As mencionadas dificuldades de tradução desses termos para nossa língua são extensivas a outros idiomas com os quais se pensa Heidegger, de sorte que poderíamos, após uma breve revisão de literatura, arrolar opções que pretendem adequadamente dar voz a estes conceitos filosóficos.

Inicialmente, para Elpidorou e Freeman (2015), não existe na língua inglesa (que possui sua origem muito próxima à língua alemã), palavras que sustentem, semanticamente e filosoficamente, o sentido proposto por Heidegger com os termos acima mencionados. Por sua vez, Macquarrie e Robinson, em sua tradução de Ser e tempo para a língua inglesa (Cf. HEIDEGGER, 1962, p.172), traduzem Befindlichkeit e Stimmung, respectivamente por: "stateof-mind" e "mood". Em nota, os tradutores apontam que as escolhas feitas implicam na perda de alguns sentidos das palavras em alemão, mas optam por essas por não haver palavras que melhor descrevam tais fenômenos. Também Greisch (1994) destaca a dificuldade da tradução destes termos para o francês, apontando que não existe correspondente imediato para Stimmung nesta língua, sendo comumente traduzido por humour, citando Michael Haar ele nos diz que: “(...) para traduzir verdadeiramente Stimmung... dever-se-ia poder de algum modo adicionar em uma só palavra, ressonância, tom, ambiente, tonalidade afetiva subjetiva $e$ objetiva - o que é evidentemente impossível" (GREISCH, 1994, p. 176). Já Befindlichkeit, que foi traduzido ao francês por Vezin como disposibilité, poderia ser melhor traduzido por affection, ainda segundo Greisch (1994). Já Borges-Duarte (2015) diz que o filósofo alemão encontra em Agostinho de Hipona o significado do conceito de abertura afetiva da experiência da vida fática marcada pelas 
| Artigo | Befindlichkeit e Stimmung, das tonalidades afetivas na analítica existencial de Heidegger |

| Dr. Roberto S. Kahlmeyer-Mertens \& Ms. Giovani Augusto dos Santos |

affectiones. $\mathrm{O}$ aventado contato com a filosofia agostiniana já se faz presente no pensamento de Heidegger desde 1921, nas lições do semestre de verão daquele ano, intitulado Agostinho e o neoplatonismo, é o que nos evidencia Borges-Duarte (2015):

A experiência fática da vida está marcada pelas affectiones (...). Heidegger, lendo Agostinho em 1921, traduz: Affektion, se se trata duma afecção corporal, por ex., uma dor física; Affekt, se não se trata meramente da impressão sensorial, mas da repercussão íntima das impressões num "estado de alma" (seelisches Zustand), implicando consciência e memória - por ex., o estar alegre ou o estar triste ou o recear (p. 4).

A autora, além dessa citação, em momento mais adiantado do mesmo texto, nos lembra que em 1924, na conferência $O$ conceito de tempo, encontramos as affectiones de Agostinho apropriadas por Heidegger por meio do termo Befindlichkeit, designando daí em diante, a abertura afetiva, estrutura fundamental do ser-aí. Por ser utilizado para traduzir para o alemão as affectiones de Agostinho e por guardar em sua origem um estar situado que é passional e ao mesmo tempo locativo, acredita-se, que Befindlichkeit pode ser traduzido, adequadamente, para o português por um encontrar-se afetivo, afeto ou afetividade. Já Stimmung vem da palavra Stimme, que significa voz e quer dizer muito mais que apenas humor ou estado-de-ânimo. Stimmung quer dizer afinação, entonação. Em face disso, destacamos que:

Algumas são as possibilidades correntes de tradução de Stimmung para o português: disposição, afeto, páthos, disposição de humor etc. Todas estas possibilidades carregam consigo um inevitável peso psicologizante e tendem a inserir no texto um conjunto de significados, do qual justamente Heidegger pretende escapar. Por isto, nós optamos neste contexto de tradução por tonalidade afetiva. Stimmung possui uma relação direta com o vocábulo Stimme, que pode ser traduzido sem mais por "voz", e com o verbo stimmen, que é utilizado corriqueiramente em linguagem musical para descrever o processo de afinação de um instrumento (CASANOVA, 2011 p. 6).

Face ao alerta a respeito da utilização das palavras "humor" e "disposição de alma" poderem acarretar confusão com termos psicológicos usuais, além de carregarem consigo carga metafísica remetendo a interioridade de um sujeito, optamos por usar tonalidade afetiva ou afinação para significar Stimmung. Com isso, desejamos significar que o ser-aí existe sempre afinado ou em sintonia com um tom. Assim nos aponta Koecher (2013), quando indica que a música é tocada 
| Artigo | Befindlichkeit e Stimmung, das tonalidades afetivas na analítica existencial de Heidegger |

| Dr. Roberto S. Kahlmeyer-Mertens \& Ms. Giovani Augusto dos Santos |

sempre em um tom, do mesmo modo a tonalidade afetiva é o que dá tom à existência, como uma sintonia contrapondo-se a ideia de subjetividade e de estados psíquicos.

Considerando o que foi dito até aqui, perguntamos: Mas o que formalmente se indicia com os conceitos de Befindlichkeit e Stimmung? Os termos disposição ou encontrar-se e humor ou estado-de-ânimo traduziriam acertadamente esses fenômenos? Para além da tradução, como compreender a Befindlichkeit e a Stimmung? São eles dois fenômenos ou um único? Essas questões dirigem a exposição no tópico que se segue.

\section{Da conceptualidade das tonalidades afetivas}

Heidegger indica que com a Befindlichkeit temos o "como" o ser-aí encontra-se ou "como" ele está em seu aí. A própria palavra utilizada pelo filósofo em alemão deixa isso muito claro, pois, sich befinden remete-se a como alguém está, acha-se ou encontra-se, como por exemplo à um estado de saúde, ou quando diz sentir-se "bem", "mal”, "feliz" ou "triste". Por sua vez, befindlich, tem o sentido de estar situado, de onde ou como alguém se encontra em algum lugar, nesse sentido se trata de uma afecção que perpassa a existência, não se restringindo unicamente a um estar locativo ou subjetivo.

A tonalidade afetiva, portanto, é uma estrutura ontológica que constitui abertura ao mundo, ou seja, diz respeito ao ser, mas se manifesta de forma mais cotidiana através das tonalidades afetivas específicas, que são concretizações ônticas do afetar-se que perpassa o ser-aí. Assim explicita-se como a abertura ontológica das tonalidades afetivas não é - de forma alguma - um estado psíquico ou de alma, pois, o pensar, o agir e o não agir só podem acontecer em meio a afinação. A partir da indicação que a tonalidade afetiva é um existencial, destaca-se que Heidegger compreende a afetividade de uma maneira diferente a como a tradição compreende. Para o filósofo alemão, a tonalidade afetiva não está mais condicionada a uma subjetividade de um sujeito em contraposição a objetividade do objeto. Ele supera a dualidade cartesiana até então fundamento da filosofia e ciência moderna e passa a compreender a tonalidade afetiva como existencial, mais originariamente do que qualquer psicologia. 
| Artigo | Befindlichkeit e Stimmung, das tonalidades afetivas na analítica existencial de Heidegger |

| Dr. Roberto S. Kahlmeyer-Mertens \& Ms. Giovani Augusto dos Santos |

Por este motivo, para nosso filósofo, qualquer tipo de tonalidade afetiva como, por exemplo, a perenidade de um afeto, o desânimo ou mesmo a passagem entre uma tonalidade afetiva para outra, não podem ser desconsideradas de um âmbito ontológico, ou seja, não podem ser consideradas como um nada, mesmo que esses fenômenos não sejam percebidos ou analisados pelo ser-aí que pode considerá-los, como fenômenos indiferentes e efêmeros. Além disso, Heidegger ainda ressalta que é justamente o fato de o ser-aí passar de uma tonalidade afetiva a outra o que comprova que ele já se encontra, desde sempre, "afinado".

Com a mudança das tonalidades afetivas tudo também muda com o ser-aí. Heidegger dá como exemplo um homem sobre o qual abateu-se grande tristeza. Para esse homem, tudo está diferente. Não obstante, tudo é como antes, pois ele ainda está no mundo junto aos outros entes. "Tudo está como antes, e, porém, tudo está diverso" (HEIDEGGER, 2011, p. 86). O autor continua dizendo que o que muda, quando mudam as tonalidades afetivas, é o como no qual o ser-aí se encontra. Esse "como" se encontra o ser-aí, que é modificado quando também as tonalidades afetivas o são, não muda por consequência destas, ou seja, não é consequência da tristeza o homem se tornar inacessível: "Ao contrário, este como co-pertence ao seu estar-triste" (HEIDEGGER, 2011, p. 86). E esse "como" o ser-aí está já é sempre transpassado por uma tonalidade afetiva. Sendo assim, esclarece-se que a tonalidade afetiva não se encontra no "interior" de um sujeito, de uma alma ou mesmo de um psiquismo. Tampouco se pode dizer que ela se encontra "fora", como um ente que vai ao encontro do ser-aí. Assim, a existência já está sempre afinada.

Outra coisa que se elucida, a partir do dito do autor, é que as tonalidades afetivas não podem ser encaradas como manifestações que passam à margem da convivência com os outros, pois a tristeza do homem pode afetar (ou afinar) o outro que venha a se coafetar (consoar) do estado deste homem, e assim passar a estar triste também. O ser-aí é ser-com, e esse existencial se manifesta também no ser-em:

Tudo se dá como se uma tonalidade afetiva sempre estivesse aí, como uma atmosfera, na qual sempre e a cada vez imergimos e desde a qual, então, seríamos transpassados por uma afinação. Tudo não se dá apenas aparentemente como se fosse assim, mas é realmente assim (...) (HEIDEGGER, 2011, p. 87-88). 
| Artigo | Befindlichkeit e Stimmung, das tonalidades afetivas na analítica existencial de Heidegger |

| Dr. Roberto S. Kahlmeyer-Mertens \& Ms. Giovani Augusto dos Santos |

Como se depreende a partir desse trecho, os entes (tanto os que possuem o modo de ser de ser-aí, quanto os outros) mostram-se ao ser-aí de modos que sempre o afinam, ou seja, a abertura possível através da tonalidade afetiva é mais originária que a abertura possível pelo conhecimento. As coisas são deste modo, pois é o próprio afetar que possibilita ao ser-aí se deparar com o seu ser enquanto aí. E a tonalidade afetiva desvela 'como alguém está e se torna'. É nesse ‘como alguém está' que a afinação do humor conduz o ser para o seu aí.

\section{Afinação, ser-lançado e outros modos de estar-situado}

É também a abertura afinada pelas tonalidades afetivas que possibilita ao ser-aí o caráter ontológico de ser-lançado (Geworfenheit), ou seja, o ser-aí lançado em seu aí se encontra no mundo afinado desde sempre por uma tonalidade afetiva. Estar desde sempre afinado por uma tonalidade afetiva quer dizer que não existe um "não ser de modo algum afinado", ser-aí já significa, desde seu fundamento estar afinado por alguma tonalidade, o que acontece sempre é uma mudança das tonalidades afetivas, o que muda "como" o ser-aí se encontra em seu aí.

Ser ou estar-lançado, assim, implica a facticidade de um mundo específico, pois, estando lançado em seu aí, o que está em jogo é o próprio ser do ser-aí, que se realiza à medida em que esse ente é o seu aí. Como diz o próprio Heidegger (2015): "Facticidade não é fatualidade do factum brutum de um ser simplesmente dado, mas um caráter ontológico do ser-aí assumido na existência, embora, desde o início, reprimida" (p. 194). Quer dizer que o ser-aí responde por seu ser. Mesmo que de uma maneira imerso na cotidianidade, o ser-aí está sempre lançado, isto é, deve sempre decidir pelo seu ser no aí que se abre pelas tonalidades afetivas, mesmo que em uma primeira aproximação esse ente não se preocupe, ou mesmo negue seu ser-lançado:

Enquanto ente entregue à responsabilidade de seu ser, ele (ser-aí) também se entrega à responsabilidade de já se ter sempre encontrado - enquanto que não é tanto fruto de uma procura direta, mas de uma fuga. A afinação não realiza uma abertura no sentido de observar o estar-lançado e sim de enviar-se e desviar-se (HEIDEGGER, 2015, p. 194195). 
| Artigo | Befindlichkeit e Stimmung, das tonalidades afetivas na analítica existencial de Heidegger |

| Dr. Roberto S. Kahlmeyer-Mertens \& Ms. Giovani Augusto dos Santos |

Na passagem, temos que esse enviar-se e desviar-se ocorre enquanto o ser-aí existe como ser-no-mundo, nos modos da ocupação e da preocupação. Significa que, na lida prática com os entes, o ser-aí "foge" de seu ser mais próprio, esquecendo-se a cada momento da maneira como está afinado, só se dando conta de qual tonalidade afetiva o afina no momento em que nela já não mais se encontra, mas faz dela objeto de sua análise objetiva:

A afinação não apenas abre o ser-aí em seu ser-lançado e dependência do mundo já descoberto a seu ser, mas ele própria é o modo de ser existencial em que o ser-aí permanentemente se abandona ao "mundo" e por ele se deixa tocar de maneira a se esquivar de si mesmo (HEIDEGGER, 2015, p. 199).

Como se vê, o ser-aí não possui modo de ser idêntico ao dos entes intramundanos. Assim, pensar o estar-lançado, ser-fora (Weg-seins), não possui, de forma alguma, um caráter de simplesmente dado e não indica um não-ser. Ao contrário, o ser-fora é justamente um modo de ser do ser-aí. Diferentemente da pedra, por exemplo, que não está aí em seu ser-fora, o ser-aí precisa do seu aí para poder estar-fora. Para exemplificar a possibilidade do ser-aí de estar e não estar aí, Heidegger diz sobre conversas cotidianas no qual o ser-aí pode "não estar presente" de fato nesta conversa e muitas vezes de maneira bem consciente. Nesse estar-ausente, o ser-aí se ocupa de si mesmo ou de outro ente. Outro exemplo apontado pelo fílósofo seria o caso da loucura. O louco, por mais consciente que esteja, pode estar alienado, estar fora. Esse poder estar fora pertence justamente ao modo de ser do ser-aí. Para o autor, a essência do ser-aí está, fundamentalmente, em um estar-fora, porque ex-siste, o ser-aí já está sempre de algum modo, necessariamente, fora de seu ser. O estar-fora não é um modo de ser que às vezes surge no ser-aí. Não é uma característica variável. Pelo contrário, estar-fora é próprio do ser-aí:

Apenas se estivermos-aí poderemos, acima de tudo, estar-fora e vice-versa. Com isto, assim como este aí e não aí, o estar-fora é algo singular. E a tonalidade afetiva está ligada, de uma certa maneira ainda obscura, com este modo singular de ser (HEIDEGGER, 2011, p. 85).

Como se compreende desde aqui, é no estar-lançado que o ser-aí se depara com o seu aí, com suas possibilidades, pois, “(...) a tonalidade afetiva coloca o ser-aí diante desse que de seu aí, o qual se lhe impõe como enigma inexorável” (HEIDEGGER, 2015, p. 195). Nesse sentido, 
| Artigo | Befindlichkeit e Stimmung, das tonalidades afetivas na analítica existencial de Heidegger |

| Dr. Roberto S. Kahlmeyer-Mertens \& Ms. Giovani Augusto dos Santos |

como enfatiza o próprio Heidegger, a tonalidade afetiva abre o ser-aí sempre para o seu aí enquanto o que é. Nesse ponto o que está em jogo não é saber a proveniência ou mesmo o destino do ser-aí, a tonalidade afetiva descerra o ser-aí para a sua facticidade, para o seu aí que é à medida que esse ente existe e o seu ter de ser recaí sobre si mesmo, como o enigma inexorável que clama por uma solução. É nesse sentido que a afinação é um ser-situado, pois, o ser-aí é sempre situado, sempre afinado afetivamente em seu estar-lançado. Destarte, tonalidade afetiva não se contrapõe à racionalidade, pelo contrário, se mostra ontologicamente, ou seja, originária ao ser-aí. Assim, não está subjugada pela primazia da razão ou da vontade, mesmo que o ser-aí possa descobrir, ou mesmo se afinar afetivamente através destas capacidades, como o próprio autor sustenta:

Que um ser-aí de fato possa, deva e tenha que se assenhorear da tonalidade afetiva através do saber e da vontade pode, em certas possibilidades da existência, significar uma primazia da vontade e do conhecimento. Isso, porém, não deve levar à negação ontológica da tonalidade afetiva enquanto modo de ser originário do ser-aí. Neste modo de ser, ele se abre para si mesma antes de qualquer conhecimento e vontade e para além de seus alcances de abertura. Ademais, nunca nos tornamos senhores da tonalidade afetiva sem afinação, mas sempre a partir de uma tonalidade afetiva contrária (HEIDEGGER, 2015, p. 195).

Diante dessas colocações, explicita-se como a abertura ontológica da tonalidade afetiva não é, de forma alguma, um estado psíquico ou de alma, pois, o pensar, o agir e o não agir só podem acontecer em meio a afinação afetiva. Assim, Heidegger retira um primado da racionalidade e da vontade, pois essas são possíveis no modo como o ser-aí se encontra, ou seja, já afinado:

O âmbito dos afetos alcança, assim, no pensamento de Heidegger, uma dimensão central. Não só se ultrapassa e vence o paradigma moderno da racionalidade, que só permitia ver o emotivo e passional como o que se lhe escapava e se lhe opunha, como, além disso, a afetividade, em íntima e originária articulação com o compreender, se converte numa das estruturas do ser na sua fenomenologia no mundo e linguagem humanos e, nessa medida, numa das características ontológicas do próprio ente, que como ser-aí, "leva o ser no seu ser" (BORGES-DUARTE, 2015, p. 6).

Não obstante, Heidegger ressalta que a exposição da constituição ontológico-existencial de toda abertura do ser-aí não tem o intento de substituir, em um campo ôntico, a ciência a uma primazia dos sentimentos. Mas é necessário perceber que qualquer conhecimento ôntico é produzido por um ente que está sempre afinado. Ainda como contraponto com as concepções 
| Artigo | Befindlichkeit e Stimmung, das tonalidades afetivas na analítica existencial de Heidegger |

| Dr. Roberto S. Kahlmeyer-Mertens \& Ms. Giovani Augusto dos Santos |

psicológicas, Heidegger diz que a tonalidade afetiva não tem sua origem nem de fora e nem de dentro do ser-aí. Vale ressaltar neste momento que a própria constituição originária do ser-aí não sustenta qualquer teoria que compreenda o ser-aí como um sujeito, ou um eu dotado de interioridade e exterioridade. Sendo assim, a tonalidade afetiva precipita-se ao ser-aí, “(...) cresce a partir de si mesmo como modo de ser-no-mundo" (HEIDEGGER, 2015, p. 196).

As tonalidades afetivas não possuem nenhuma consistência, pelo contrário, são extremamente inconsistentes e por esse motivo mudam de maneira constante. Segundo Heidegger (2011): "Elas não são senão o brilho e a cintilância, ou, inversamente, o sombrio que se encontra por sobre os adventos anímicos” (p.84). Como modo de ser-no-mundo, o afetar-se é “(...) um modo existencial básico da abertura igualmente originária de mundo, de co-ser-aí e existência, pois também este modo é em si mesmo ser-no-mundo" (HEIDEGGER, 2015, p. 196). Elpidorou e Freeman (2015) destacam que a afetividade tem importância fundamental no pensamento de Heidegger, pois, o ser-aí só é aberto ao mundo por ter seu ser fundamentalmente afinado, sempre e a cada vez, por uma tonalidade afetiva. A tonalidade afetiva determina o "como" do ser-aí, por esse motivo estas não são apenas formas ou padrões modais, não são sentimentos, vivências, estados de consciência, adventos ou meros estados da alma. São, justamente, jeitos de estar afinado, como uma melodia que fornece ao ser-aí um tom, que afina o modo e o como de seu ser no aí. Desse modo, as tonalidades afetivas são, positivamente:

(...) modos fundamentais, o jeito fundamental como o ser-aí enquanto ser-aí é. (...) à medida que a tonalidade afetiva é o jeito originário, no qual todo e qualquer ser-aí é como ele é, ela não é o maximamente inconstante, mas o que dá ao ser-aí desde o princípio consistência e possibilidade (HEIDEGGER, 2011, p. 88).

A partir daqui, divisa-se duas determinações essenciais que Heidegger atribui à tonalidade afetiva, a saber: ela abre o ser-aí ao estar-lançado e ela é abertura da totalidade do ser-no-mundo. Não obstante, o autor ainda acrescenta uma terceira determinação: a tonalidade afetiva é o que, existencialmente, constitui a abertura mundana do ser-aí. Isso significa que somente em um modo afinado é que os entes intramundanos podem vir ao encontro do ser-aí e, de alguma maneira, estimular os sentidos deste ente. Somente porque a tonalidade afetiva abre o aí do ser-aí é que os entes intramundanos podem tocá-lo desta ou daquela maneira. Por isso, as tonalidades afetivas 
| Artigo | Befindlichkeit e Stimmung, das tonalidades afetivas na analítica existencial de Heidegger |

| Dr. Roberto S. Kahlmeyer-Mertens \& Ms. Giovani Augusto dos Santos |

não podem ser compreendidas, de modo algum, como um simples jogo da relação ser-aí e mundo, ou mesmo ser-aí com outro ser-aí, mas é só na tonalidade afetiva que um ente intramundano pode parecer, por exemplo, ameaçador:

É justamente na visão instável e de tonalidade afetiva variável do "mundo" que o manual se mostra em sua mundanidade específica, a qual nunca é a mesma. A observação teórica sempre reduziu o mundo à uniformidade do que é simplesmente dado; dentro dessa uniformidade subsiste encoberta sem dúvida uma nova riqueza de determinações, passíveis de descoberta (HEIDEGGER, 2015, p. 197).

Heidegger diz serem diversos os modos das tonalidades afetivas que se revela no ser-aí, por esse motivo, o filósofo atesta não ser possível fazer uma análise sobre todos esses modos de abertura. Em sua preleção Os conceitos fundamentais da metafisica: mundo, finitude, solidão, ministrada no semestre de inverno de 1929/30, Heidegger dedica todo o primeiro capítulo da primeira parte à tonalidade afetiva. Como indica o próprio título do capítulo (a saber, $O$ despertar de uma tonalidade afetiva fundamental de nosso filosofar), o autor busca mostrar que é possível despertar as tonalidades afetivas. E mais, pode-se depreender desse título que Heidegger considera alguma tonalidade afetiva fundamental a maneira como ele, e seus alunos, propunhamse a filosofar. Mas afinal o que o filósofo quer dizer com despertar? E qual tonalidade afetiva ele considera como fundamental para o seu modo de filosofar?

Para Heidegger, despertar alguma tonalidade afetiva fundamental parte inicialmente de uma escolha. Justamente há que escolher qual tonalidade afetiva fundamental despertar. Entretanto, além de uma escolha é necessário saber sobre qual caminho a tonalidade afetiva fundamental escolhida pode ser desperta. Mas, segundo o autor, não é possível alcançar uma tonalidade afetiva por meio de um estímulo artificial, seja ele interno ou externo. O que se pode é deixar a tonalidade afetiva aparecer, haja vista que ela já sempre está aí:

Não é justamente isto o que menos se deixa inventar, mas que sempre se abate sobre alguém? Não é justamente isto que estamos em condições de impingir, mas que se conforma por si mesmo? Não é justamente isto que não se alcança através da mera coação, mas em que caímos? Neste sentido, podemos e temos o direito a uma tal tonalidade afetiva quando a deixamos ser e não a alcançamos através de um impulso artificial e arbitrário. Ela já sempre precisa estar aí. (HEIDEGGER, 2011, p. 78). 
| Artigo | Befindlichkeit e Stimmung, das tonalidades afetivas na analítica existencial de Heidegger |

| Dr. Roberto S. Kahlmeyer-Mertens \& Ms. Giovani Augusto dos Santos |

Sendo assim, o que se pode fazer é apenas compreender uma tonalidade afetiva que já sempre está aí. Heidegger nos diz que, mesmo que se diga que a tonalidade afetiva é compreendida de maneira diferente, como se constata a cor do cabelo de uma pessoa, a primeira, assim como a segunda, é sempre algo que é compreensível nesta pessoa. Se não se compreende a tonalidade afetiva como um algo simplesmente dado na pessoa, como algo simplesmente presente, como um dado ou como uma universalidade, então, como é possível constatá-la como pertencente à pessoa? Até mesmo a requisição de informações sobre determinada tonalidade afetiva não é suficiente para constatá-la, pois: "É possível que não pertença à compreensão de uma tonalidade afetiva apenas o fato de possuí-la, mas também o fato de se estar correspondentemente afinada com ela" (HEIDEGGER, 2011, p. 78). Disso, pode-se concluir que o ser-aí não possui a tonalidade afetiva da maneira que usualmente compreendemos o verbo possuir. Ser-aí não é proprietário, não mantém em seu poder ou mesmo faz uso das tonalidades afetivas de acordo com sua vontade. Portanto, o próprio filósofo nos diz que a tarefa de compreender de maneira objetiva as tonalidades afetivas é um empreendimento duvidoso ou mesmo impossível.

As tonalidades afetivas também não possuem um caráter de universalidade ou de verificabilidade científica aos moldes das ciências positivas. Elas não são constatáveis através da observação. $\mathrm{O}$ fato de alguém negar constatar em si mesmo tais tonalidades afetivas também não representa uma objeção em sua constatação. Não é possível nem mesmo através de uma psicanálise assegurar a constatação objetiva das tonalidades afetivas. Assim, nos assevera nosso filósofo:

Tonalidades afetivas não são entidades que se deixam constatar em mais de uma maneira universalmente válida: elas não são como um fato, em direção ao qual podemos conduzir qualquer pessoa. Uma tonalidade afetiva não apenas não se deixa constatar, mas também não deve ser constatada - mesmo que ela se deixe constatar. (...). No que se refere à tonalidade afetiva, todo e qualquer tornar consciente significa uma destruição. De qualquer modo, ele produz no mínimo uma alteração; e, para nós, em meio ao despertar de uma tonalidade afetiva, tudo depende de deixar esta tonalidade afetiva ser como ela deve ser enquanto esta tonalidade afetiva. $\mathrm{O}$ despertar é um deixar ser da tonalidade afetiva, que antes disto dorme explicitamente; (...) A tonalidade afetiva está de certa maneira aí e não está aí (HEIDEGGER, 2011, p. 85). 
| Artigo | Befindlichkeit e Stimmung, das tonalidades afetivas na analítica existencial de Heidegger |

| Dr. Roberto S. Kahlmeyer-Mertens \& Ms. Giovani Augusto dos Santos |

Essas falas de Heidegger indiciam o motivo de utilizar o verbo "despertar" para se referir ao seu empreendimento em relação às tonalidades afetivas e não o verbo constatar e por despertar o filósofo compreende um fazer-com-que-acorde: “'O que dorme’ está ausente de uma maneira característica, e, contudo, está aí” (HEIDEGGER, 2011, p. 79). Por esse motivo, o autor diz que a tonalidade afetiva possui um ser que contradiz os moldes da filosofia tradicional, pois possui uma característica de estar aí e não estar aí ao mesmo tempo, o que seria contraditório segundo a lógica e, portanto, impossível. Mas o que pode se despertar já está de alguma maneira presente, mesmo que adormecido. Portanto, para compreender o despertar da tonalidade afetiva é preciso, segundo o filósofo, colocar em questão o princípio básico metafísico da não contradição. Esse empreendimento já se faz presente no pensamento de Heidegger em sua ontologia fundamental, na qual apresenta como um dos subprojetos a destruição da história da ontologia. E essa superação só é possível se o fio condutor do filosofar for o ser-aí: "Pois, sabemos, a partir da nossa própria experiência enquanto homens, que algo pode estar presente em nós, e, apesar disto, não estar presente; que há processos que nos pertencem e que, contudo, não ganham o interior de nossa consciência" (HEIDEGGER, 2011, p. 79). A partir desta colocação de Heidegger pode parecer que o Princípio de Não-Contradição é superado pelo conceito psicanalítico do inconsciente e, assim, a tonalidade afetiva é algo que está contido de maneira latente nesse inconsciente e poderia emergir ao consciente e afinar o ser-aí em sua existência, e o despertar seria apenas um processo de trazer à consciência aquilo que já está aí, adormecido no inconsciente. Entretanto, esta ideia já é combatida por Heidegger (2011) no título do subitem no qual ele faz esta comparação, a saber O ser-ai e o não-ser-aí da tonalidade afetiva não é apreensivel através da diferenciação entre ter consciência e inconsciência. Portanto, como fica claro o despertar e o dormir não tem correlação com as noções de consciente e inconsciente, haja vista que, para Heidegger, até mesmo o sonho seria um fenômeno de consciência.

Se despertar uma tonalidade afetiva não equivale ao processo de tornar consciente o que estava inconsciente, então, o que é este despertar? "Despertar uma tonalidade afetiva diz muito mais deixá-la vir-a-estar desperta, e, enquanto tal, justamente deixa-la ser." (HEIDEGGER, 2011, p. 80). E nesse sentido, justamente quando tomamos consciência de uma tonalidade afetiva a fim de conhece-la intelectualmente, tornando-a um objeto do saber, o que se consegue é o oposto do 
| Artigo | Befindlichkeit e Stimmung, das tonalidades afetivas na analítica existencial de Heidegger |

| Dr. Roberto S. Kahlmeyer-Mertens \& Ms. Giovani Augusto dos Santos |

despertar, mais que isso, neste processo a tonalidade afetiva é enfraquecida, modificada ou até mesmo destruída. Diante disso, novamente o autor critica a tradição filosófica, que compreende o homem como dotado de razão, pois, segundo ele, essas concepções tradicionais sobre o homem não são suficientes se o objetivo for aproximar das tonalidades afetivas a fim de despertá-las, pelo contrário, essas concepções levaram a um total desconhecimento da essência das tonalidades afetivas.

Ao fim, tendo apresentado os conteúdos temáticos necessários aos desdobramentos de nosso trabalho, passemos agora a suas conclusões.

\section{Considerações finais}

No artigo que ora se conclui, expusemos como o filósofo compreende as tonalidades afetivas no projeto da analítica do ser-aí. Para Heidegger, tendo em vista a constituição fundamental desse ente, a saber sua abertura existencial e indeterminação essencial, os fenômenos afetivos não podem ser compreendidos com acento psicologista, assim, tonalidades afetivas não são "emoções", "humores", "disposições de ânimo", "estados da alma" ou outra designação de cariz subjetivo.

Vimos também, por meio de uma apreciação das traduções destinadas aos termos que dão voz a nossa temática, que a escolha das palavras Befindlichkeit e Stimmung são usadas para se referir a estes fenômenos buscando evitar conotações psicológicas. Do mesmo modo, procuramos evidenciar que Befindlichkeit e Stimmung indicam duas faces de um mesmo fenômeno, sendo suas modulações ôntico-ontológico. Tais expressões desejam grifar a estrutura fundamental de abertura de mundo do ser-aí, isto é, sublinhar que o ser-aí se encontra, desde sempre, em mundo, jogado em meio aos entes intramundanos.

Como vimos, estando-lançado no mundo, o ser-aí está em meio aos entes, primeiro ele encontra-se, afeta-se, afina-se de algum modo com estes entes, para só depois conhecê-los. É assim que as tonalidades afetivas acentuam o primeiro modo de abertura do aí do ser-aí; marcam seu caráter de lançado em meio aos entes e proporcionam abertura ao mundo que também é um 
fenômeno de co-ser-aí. Enfatizamos, por fim, que tanto Befindlichkeit quanto Stimmung grifam o caráter de abertura ao mundo do ser-aí.

\section{Referências bibliográficas}

HEIDEGGER, M. Being and time. Translation by John Macquarrie \& Edward Robinson. Oxford, UK: Blackwell Publishers, 1962.

. Os conceitos fundamentais da metafísica: mundo, finitude, solidão. Tradução de Marco Antônio Casanova. 2. ed. - Rio de Janeiro: Forense Universitária, 2011. . Sein und Zeit. In: Gesamtausgabe. Band 2. Framkfurt am Main: Vittorio Klostermann, 1977.

. Ser e tempo. Tradução de Márcia Sá Cavalcante. 10. ed. Petrópolis, RJ: Vozes; Bragança Paulista, SP: Editora Universitária São Francisco, 2015.

BORGES-DUARTE, I. A afectividade no caminho fenomenológico heideggeriano. In.

Phainomenon - Revista de fenomenologia (Lisboa), v. 24, 2012, pp. 43- 62. . O afecto na Análise Existencial heideggeriana. In: CASANOVA, M. A.; ESTRADA, P. C. D.. Fenomenologia Hoje V. Fenomenologia e Filosofia Prática. Atas do V Congresso Luso-Brasileiro de Fenomenologia. Rio de Janeiro, Via Verita, 2015. p. 3-19. Disponível em: http://dspace.uevora.pt/rdpc/handle/10174/18116 Acesso em: 28 de jun. de 2018.

CASANOVA, M. A. Mundo e historicidade: leituras fenomenológicas de Ser e tempoVolume 1 - Existência e mundanidade. Rio de Janeiro: Via Verita, 2017. . Notas do tradutor. In. HEIDEGGER, Martin. Os conceitos fundamentais da metafisica: mundo, finitude e solidão. Tradução de Marco Antonio Casanova. Rio de Janeiro: Forense Universitária, 2011.

ELPIDOROU, A.; FREEMAN, L. Affectivity in Heidegger I: moods and emotions in Being and time. In: Philosophy Compass. v. 10. 2015. p. 661-671. Disponível em: 
https://www.researchgate.net/publication/280134255_Affectivity_in_Heidegger_I_Moods_and_ Emotions_in_Being_and_Time Acesso em: 17 de set. de 2018.

GREISCH, J. Ontologie et temporalité: Esquisse d'une interprétation intégrale de Sein und Zeit. Paris: Presses Universitaires de France, 1994.

FÉLIX, W. Da historicidade das disposições. In: Aoristo - International Journal of Phenomenology, Hermeneutics and Metaphysics. n. 4. v.1. 2019. p. 24-40. Disponível em: http://e-revista.unioeste.br/index.php/aoristo/article/view/23248/14646 Acesso em: 19 de mar. de 2020.

KOECHER, J. Heidegger's concept of Stimmung and its relevance to the practice of psychotherapy. In: Existential Analysis. v. 24. n. 2. 2013. p. 263-267. Disponível em: http://go.galegroup.com/ps/anonymous?id=GALE\%7CA346627557\&sid=googleScholar\&v=2. 1\&it $=\mathrm{r} \&$ linkaccess $=\mathrm{abs} \& \mathrm{issn}=17525616 \& \mathrm{p}=\mathrm{AONE} \& \mathrm{sw}=\mathrm{w}$ Acesso em: 17 de set. de 2018. XOLOCOTZI, Á. Introducción. In: Studia Heideggeriana. v. 4. 2015. p. 9-20.

Recebido em: 19/03/2020 | Aprovado em: 15/04/2020 